\title{
Arbor
}

\section{La familia española en el contexto de la Unión Europea}

\author{
Gerardo A. Meil
}

Arbor CLXXVIII, 702 (Junio 2004), 421-449 pp.

La vida familiar en España como en el resto de países de la UE y más en general de todos los países industriales avanzados se encuentra inmersa en un profundo proceso de cambio que ha sido conceptuado de distintas formas según sea la tradición sociológica desde la que se argumente. Una de las conceptuaciones más conocidas es la debida a Ulrich Beck (1986), que describe este proceso como parte de un proceso más general de individualización creciente. El argumento central de la tesis de la individualización puede considerarse que enlaza con, desarrollándola y actualizándola, la tesis clásica de M. Weber de que el advenimiento de la sociedad moderna está ligado a un proceso de desencantamiento del mundo y la racionalización sistemática de todos los ámbitos de la vida que dan lugar a la emergencia del moderno individuo formalmente libre (como ciudadano, obrero, etc.). Así, según Beck (1986), si con el advenimiento de la sociedad moderna se produjo un proceso de liberación de los hombres de las ataduras estamentales y se incrementaron su capacidad y sus posibilidades de acción individual, también durante la segunda mitad del siglo XX (con la emergencia de la sociedad postmoderna o postindustrial) se ha registrado un renovado empuje del proceso de modernización e individualización, que se ha traducido en nuevas liberaciones de las «ataduras estamentales», pérdida de referentes culturales para organizar la acción individual e incrementos de las opciones de acción individual tanto en la esfera del trabajo, como de la estratificación social en clases sociales o en el ámbito de la política, así como en el ámbito del matrimonio y la familia, interesando en este contexto únicamente esta última dimensión.

Dentro de este proceso de individualización, las fases de la vida, los hitos en las biografías individuales dejan también de estar culturalmen- 
te fijados y las certezas del pasado pierden su validez. Son los propios individuos quienes tienen que planificar su vida y las biografías individuales dejan de estar «normalizadas», para pasar a ser «biografías elegidas»: «la individualización significa en este sentido que las biografías de las personas han dejado de estar fijadas externamente, que están abiertas y sujetas a decisiones individuales y estas decisiones han pasado a formar parte de la acción individual... Las decisiones sobre estudios, formación profesional, trabajo, residencia, matrimonio, número de hijos, etc. y todas las decisiones adicionales que ello comporta, no sólo pueden tomarse, sino que tienen que tomarse (explícitamente)» (Beck, 1986: 216; BeckGernsheim, 1998: 54). Con la liberación de las ataduras tradicionales y de las normas tradicionales para la acción, el individuo pasa a convertirse en una instancia de planificación existencial, con todos sus riesgos, sus aciertos y sus errores: la prevención se convierte en el imperativo normativo de la sociedad individualizada. El paso desde la planificación externa por la sociedad a la planificación individual de las propias biografías individuales significa también que las biografías se han vuelto menos lineales con la generalización del divorcio y la formación de nuevas uniones. La individualización ha comportado el paso desde «la biografía normal» a la «biografía flexible» (Bastelbiographie) (Beck, 1986: 217; Beck y Sopp, 1997: 11; Beck-Gernsheim, 1998: 54). La «biografía flexible» denota la fragilidad de las uniones y la pérdida de las certezas tradicionales, significa la capacidad de decisión sobre el futuro y la necesidad de planificación del futuro individual; no es sino reflejo de que con la individualización el curso de la vida se ha convertido en una obra de ingeniería (Beck-Gernsheim, 1998:54).

La consecuencia de la pérdida del control social sobre los proyectos de vida en pareja y en familia y la consiguiente privatización de las decisiones en este ámbito es la pluralización de las formas de vida familiar. Esta tesis de la pluralización de las formas de vida así como la tesis de las «biografías flexibles» ha sido objeto de una fuerte polémica, en la que se argumenta (Nave-Herz, 1999) que si bien se ha producido una reducción del control social sobre las formas sociales de ordenar las relaciones de pareja, emergiendo distintas formas de ordenarlas como son las uniones de hecho o el vivir juntos pero separados (LAT) además del matrimonio, por lo que se refiere a las relaciones padres - hijos no cabe hablar de una pluralización de formas familiares. En otros términos, si bien se puede hablar de una diferenciación social del subsistema pareja en matrimonios y uniones de hecho, no cabe hablar de una diferenciación social del subsistema relaciones filiales, por más que haya estilos distintos de so- 


\section{La familia española en el contexto de la Unión Europea}

cialización o haya familias monoparentales (ahora derivadas del divorcio o separación) y biparentales.

Sin querer entrar en la polémica sobre cómo conceptuar el proceso de cambio familiar, lo que se quiere argumentar es que la pérdida del control social sobre los proyectos individuales de vida en pareja y en familia tiene un alcance muy similar en todos los países industriales y en particular en los de la UE, pudiéndose hablar de una convergencia en esta dimensión de la realidad familiar. No cabe igual diagnóstico, sin embargo, en lo que se refiere a los comportamientos efectivos, registrándose un proceso de pluralización de las formas de vida muy diferente de unos países a otros. En lo que sigue abordaremos en primer término las principales características del cambio en los valores y actitudes hacia la pareja y la vida familiar en general, esto es, a lo que Beck denomina «liberación de las ataduras tradicionales» $\mathrm{y}$ «desencantamiento familiar», para a continuación abordar las características de la pluralización de la vida en pareja y en familia en España, centrando la atención, sobre todo, en una de las dimensiones de esta pluralización como son las uniones de hecho.

\section{La transformación de los valores familiares en España}

La primera evidencia de este proceso de privatización de «liberación de las ataduras tradicionales» se encuentra en la valoración social y en la práctica de la sexualidad socialmente considerada legítima. Así, tal como se puede observar en la tabla 1, las relaciones sexuales prematrimoniales están plenamente aceptadas y sólo una minoría las considera moralmente inaceptables, siendo sobre todo las personas de más edad y más tradicionales quienes las rechazan. Incluso entre las personas que se consideran muy religiosas, sólo un $47 \%$ rechaza en todos los casos este tipo de relaciones. Esta aceptación de las relaciones prematrimoniales no es además un fenómeno nuevo, sino que ya era mayoritaria su aceptación en la década de los ochenta cuando la mitad de los encuestados (48\%) mayores de 18 años se mostraba de acuerdo con la proposición «cada uno debe tener la posibilidad de disfrutar de completa libertad sexual, sin limitaciones», proporción que se elevaba a tres de cada cuatro entre los más jóvenes, pero reduciéndose a uno de cada cinco entre los mayores de 65 años (Orizo, 1.990: 76). Por otro lado, no se trata sólo de tolerancia hacia la sexualidad prematrimonial, sino también de su práctica. Al tiempo que asistimos a un retraso sistemático en la edad al nacimiento del primer hijo 
(que ha pasado de 24,8 años en 1979 a 29,0 en 1999), la edad declarada en las encuestas a la que se tiene el primer contacto sexual desciende. Según la encuesta de juventud del año 2000 (CIS, 2000), la proporción de varones de 18 a 19 años que no había tenido relaciones sexuales de ningún tipo era del $33 \%$, si bien era un $44 \%$ los que habían tenido «relaciones sexuales completas (con penetración)», proporción que va aumentando con la edad hasta alcanzar un 4 y $84 \%$ respectivamente entre los que tenían 25 a 29 años. En el caso de las mujeres, aunque las proporciones son algo menores, las diferencias no son muy grandes, pues entre las jóvenes de 18 a 19 años la proporción de las que no habían tenido relación sexual de ningún tipo alcanzaba el 37\%, siendo otro 37\% las que habían tenido «relaciones sexuales completas (con penetración)», proporciones que aumentan hasta el 7 y $78 \%$ respectivamente entre las que tenían 25 a 29 años en el momento de la entrevista. La mediana de edad de inicio de las relaciones sexuales completas, entre quienes las han tenido, se sitúa entre los 16,6 años entre los varones más precoces y 18,6 años entre las mujeres menos precoces. Los datos que proporciona la encuesta FFS/ONU del CIS (1995) no difieren sustancialmente de estos datos, siendo lo más llamativo que entre los varones y mujeres entrevistadas de más edad (40 a 49 años) la mediana de inicio de las relaciones sexuales no está tan alejada de la de los jóvenes del 2000, al situarse en 19,9 y 22,2 años respectivamente. La sexualidad, para la gran mayoría de los jóvenes adultos encuestados, tanto varones como mujeres, se ha convertido en un espacio de expresión privado y de realización personal que no está en absoluto condicionado ni a la reproducción ni al matrimonio.

Esta privatización de la sexualidad legítima y su consideración como un aspecto esencial de la realización personal se ha extendido no sólo a las relaciones heterosexuales de los jóvenes, sino que ha alcanzado también a las relaciones entre personas del mismo sexo. La aceptación de este tipo de relaciones sexuales está, sin embargo, menos extendida que aquéllas, aunque las actitudes en este sentido están cambiando rápidamente, tal como se puede observar también en la tabla 1: a finales de los 90, sólo uno de cada tres entrevistados las consideraba moralmente inaceptables y la condena de la homosexualidad ha pasado a ser considerada como «políticamente incorrecta», lo que no significa que no exista discriminación en función de la orientación sexual, como la hay también en función del sexo. Como es fácilmente imaginable, las actitudes en este sentido no están homogéneamente distribuidas a lo largo de la sociedad: los no creyentes, jóvenes, universitarios, solteros o separados/divorciados y con ideología de izquierda o centro no lo condenan en una proporción de 2 por cada 3 o 


\section{La familia española en el contexto de la Unión Europea}

más, mientras que los más mayores, practicantes de cualquier religión, con estudios primarios o menos, viudos o casados y de derechas consideran en una proporción de 2 por cada 3 o más que este tipo de relaciones siempre está mal. Comparativamente con otros países de la Unión Europea, sin embargo, y según los resultados de Eurobarómetro (1.993: 94 y ss), España se sitúa entre los países que muestran una actitud más favorable hacia los derechos de los homosexuales. Así, los españoles se sitúan en el tercer lugar tras holandeses y daneses en la adhesión a la propuesta de que la parejas del mismo sexo tengan los mismos derechos que los casados aún cuando su relación sea «sin papeles» o en el reconocimiento de su derecho a casarse. Incluso un $60 \%$, sólo superado en Dinamarca, Holanda y Reino Unido creen que deberían tener el derecho de herencia de su pareja de la misma forma que lo tienen los matrimonios y, en lo que al reconocimiento del derecho a adoptar niños se refiere, las expresiones de apoyo, aunque limitadas a un tercio de los encuestados, son con las expresadas por los holandeses las más frecuentes.

TABLA 1. Valoración moral del mantenimiento de distintos tipos de relaciones sexuales. En porcentajes

\begin{tabular}{|l|c|c|c|c|c|c|c|}
\hline & \multicolumn{2}{|c|}{ Prematrimoniales } & \multicolumn{2}{c|}{$\begin{array}{c}\text { Entre } \\
\text { adoles- } \\
\text { centes }\end{array}$} & \multicolumn{2}{c|}{ Extramatrimoniales } & \multicolumn{2}{c|}{$\begin{array}{c}\text { Entre adultos del } \\
\text { mismo sexo }\end{array}$} \\
\cline { 2 - 8 } & $\mathbf{1 9 9 4}$ & $\mathbf{1 9 9 8}$ & $\mathbf{1 9 9 4}$ & $\mathbf{1 9 9 4}$ & $\mathbf{1 9 9 8}$ & $\mathbf{1 9 9 4}$ & $\mathbf{1 9 9 8}$ \\
\hline Siempre está mal & 18 & 15 & 56 & 73 & 61 & 39 & 30 \\
\hline Casi siempre está mal & 7 & 6 & 17 & 12 & 13 & 6 & 6 \\
\hline Está mal sólo algunas veces & 8 & 13 & 9 & 6 & 13 & 5 & 9 \\
\hline No está mal en absoluto & 58 & 61 & 13 & 5 & 8 & 36 & 45 \\
\hline Depende & 4 & - & 0 & 4 & - & 6 & - \\
\hline No sabe/no contesta & 4 & 5 & 6 & 0 & 5 & 8 & 9 \\
\hline Total & 100 & 100 & 100 & 100 & 100 & 100 & 100 \\
\hline
\end{tabular}

Fuente: CIS, Estudio nro. 2.113, Familia, septiembre 1.994 y Estudio 2.301, Religión, septiembre 1998 (Base: población mayor de 18 años).

En España se ha asistido, por tanto, a un incontestable proceso de separación de la sexualidad legítima del matrimonio, similar al que se ha registrado en otros países europeos. Esta separación entre sexualidad y matrimonio opera, no obstante, únicamente en la fase de constitución de una pareja, pues la sexualidad extramatrimonial aunque legalmente ha dejado de constituir un delito, sigue constituyendo, en España como en otros paí- 
ses, una de las principales razones que justifican el divorcio y la fidelidad sexual es una de las dimensiones que se consideran más importantes para el éxito de la vida en pareja. No obstante, como puede observarse en la tabla 1, las actitudes en este sentido parece que están cambiando también. Así, la proporción de entrevistados que rechazan en todo caso este tipo de relaciones está descendiendo y la tolerancia, más quizá que la aceptación, parece que está creciendo. Esta mayor tolerancia no se da sólo entre los varones, sino que también cabe encontrarla entre las mujeres en una proporción muy similar ${ }^{1}$ y son los más jóvenes, con mayor nivel de estudios y menor compromiso religioso los que se muestran más tolerantes. El vínculo conyugal juega también un papel importante, de suerte que son quienes conviven en unión de hecho quienes en menor medida rechazan en cualquier caso las relaciones extraconyugales, pero entre los matrimonios están empezando también a cambiar las actitudes en este sentido (sólo el $55 \%$ de los/as entrevistados/as en una unión de hecho menores de 50 años consideraban que estaba siempre o casi siempre mal frente a un $72 \%$ de los/as casados/as de la misma edad -CIS, 1998-). En este sentido parece que se está apuntando también una tendencia hacia la diferenciación entre la fidelidad amorosa y la fidelidad sexual. La encuesta sobre relaciones de pareja realizada por el CIS en 1995 proporciona datos adicionales para fundamentar esta tesis. Así, sólo a un 70\% de los varones y a un $75 \%$ de las mujeres que llevaban más de 3 años en una relación de pareja (con o sin convivencia) les resultaba mucho o bastante insoportable la idea de que su pareja no le fuera sexualmente fiel y un 48 y $49 \%$ respectivamente estaban muy o bastante de acuerdo con la proposición «si mi pareja tuviera una relación sentimental especial con otra persona, me sentiría más celoso que si tuviera relaciones sexuales con ella». A la hora de llevar a la práctica esta diferenciación, no obstante, las diferencias en función del sexo son abrumadoras: mientras un $81 \%$ de los varones con una relación de pareja (con o sin convivencia) señalaron que nunca había mantenido relaciones sexuales con otra persona desde que comenzó su relación de pareja, entre las mujeres la proporción se elevaba al $96 \%$ y mientras la proporción de varones con pareja que rechazan plenamente el deseo de tener relaciones sexuales esporádicas con otras personas se elevaba al 76\%, entre las mujeres alcanzaba el 91\% (CIS, 1995). Dadas estas diferencias, habría que preguntarse, no obstante, si más que de diferenciación entre fidelidad sexual y fidelidad amorosa no se trata más que de una vuelta, con nuevas vestiduras ideológicas, hacia el patriarcado tradicional.

Corolario de esta separación de sexualidad legítima y matrimonio es la aceptación del principio de la planificación familiar, pero no en los mis- 


\section{La familia española en el contexto de la Unión Europea}

mos términos que durante la transición demográfica, en la que el número de hijos se limitaba de forma efectiva (como lo demuestra la constante reducción del tamaño de las familias) al tiempo que la utilización de métodos anticonceptivos estaba estigmatizada, sino a través precisamente de la utilización de tales métodos. Así, a comienzos de los 90, sólo un $15 \%$ de los encuestados (en su gran mayoría mayores de 50 años) eran partidarios de tener «los hijos que vengan», mientras que cuatro de cada cinco encuestados solteros o casados se mostraban favorables a la planificación familia (Alberdi, Flaquer e Iglesias de Ussel, 1994: 132 y ss.). Entre los jóvenes de 15 a 29 años entrevistados en el 2000 por el CIS, la proporción que señaló «los que vengan» se elevó únicamente al 1,1\%.

Por lo que se refiere a las actitudes hacia las uniones de hecho, éstas han dejado primero de ser consideradas como algo inmoral, para después ser toleradas como otra forma de vida en pareja y pasar a ser consideradas como «algo que no se juzga», hasta finalmente ser vistas como un antídoto al divorcio y, por tanto, como una fórmula recomendable para comprobar antes del matrimonio el grado de compenetración. Y todo este largo proceso de redefinición social, que es paralelo y corolario del cambio en las actitudes hacia la sexualidad no matrimonial, en el plazo de poco más de dos décadas. El desarrollo de esta tolerancia y su conversión en asunto privado es, ante todo, un fenómeno generacional, que, poco a poco, ha ido convirtiéndose en un aspecto de la cultura familiar predominante.

TABla 2. Actitudes hacia las uniones de hecho. Porcentaje de población según su edad que está de acuerdo con las siguientes frases

\begin{tabular}{|c|c|c|c|c|}
\hline & \multicolumn{2}{|c|}{1994} & \multicolumn{2}{|c|}{1998} \\
\hline & $18-49$ & $50 y+$ & $18-49$ & $50 y+$ \\
\hline $\begin{array}{l}\text { Está bien que los que componen una pareja vivan } \\
\text { juntos aunque no tengan intención de casarse. / Es } \\
\text { una buena idea que dos personas que mantengan } \\
\text { una relación de pareja vivan juntas, aunque no } \\
\text { tengan intención de casarse }\end{array}$ & 79 & 39 & 86 & 47 \\
\hline $\begin{array}{l}\text { Para una pareja que tiene intención de casarse es } \\
\text { una buena idea vivir antes juntos/ Es una buena } \\
\text { idea que dos personas que mantengan una relación } \\
\text { de pareja vivan juntas, si tienen intención de } \\
\text { casarse en un futuro }\end{array}$ & 70 & 35 & 88 & 56 \\
\hline $\begin{array}{l}\text { Personalmente, vivir en pareja sin estar casados le } \\
\text { parece un comportamiento moralmente } \\
\text { inaceptable* }\end{array}$ & & & 7 & 34 \\
\hline
\end{tabular}

Leyenda: La diferencia hasta 100 de cada uno de los valores es el porcentaje de entrevistados que no están de acuerdo con las citadas proposiciones, están indecisos, no saben o no contestan.

Fuente: CIS (1994), Familia, estudio $\mathrm{n}^{\circ} 2.113$ y CIS (1998), Religión, estudio $\mathrm{n}^{0} 2.301$. 
Así, datos de encuesta de 1992 evidencian que la calificación como algo negativo (frente a positivo) de la tendencia al aumento del número de parejas que no están casadas pero que cohabitan es minoritaria entre las generaciones más jóvenes, pero relativamente extendida entre los más mayores (un 31\% del total de encuestados mayores de 18 años así lo consideran, pero mientras entre los mayores de 60 años es un $52 \%$, entre los menores de 40 años sólo alcanza un 11\%) (CIS, 1992). Frente a esta división de opiniones, a principios de la década siguiente sólo un $10 \%$ de los entrevistados mayores de 18 años ( 3 entre los menores de 50 y $20 \%$ entre los mayores) consideraba grave que un hija conviviera en pareja sin estar casada y sólo un $16 \%$ (9 frente a $26 \%$ respectivamente) consideraba grave que una hija suya tuviera un hijo sin estar casada ${ }^{2}$. Si a principios de la década de los 90, las uniones de hecho eran aceptadas como una fórmula plenamente válida para materializar un proyecto de vida en común por las nuevas generaciones de jóvenes y mayormente también por sus padres, pero no por los abuelos, una década más tarde esta aceptación se había generalizado ya a todas las edades, quedando su rechazo limitado a determinados grupos sociales, especialmente a los más mayores y más religiosos. No obstante, las actitudes en este sentido son bastante ambiguas, pues como puede observarse en las tablas 3 y 4, a pesar de considerarse como algo privado, moralmente no condenable e incluso como una buena fórmula para comprobar el ajuste emocional, la mayoría de la población adulta considera, sin embargo, que es mejor casarse que cohabitar, lo que probablemente se traduzca en una presión hacia los hijos para que «finalmente» se casen, pero sin hacer de ello un drama si no lo hacen (Paris, 2000).

Comparativamente con otros países europeos occidentales, la aceptación social de las parejas de hecho ha sido muy rápida y así a comienzos de la década de los noventa, aunque cabía encontrar un mayor rechazo moral que en los países escandinavos, su consideración como un asunto privado que no procede juzgar en términos morales estaba igual de extendida que en los demás países del centro de Europa. El alcance del rechazo moral explícito hacia esta forma de materializar un proyecto de vida en común no era en España muy diferente del que cabía encontrar en países como el Reino Unido, Alemania o Bélgica, tal como puede observarse en la tabla 3. Una década más tarde, y por lo señalado en el párrafo anterior, no hay razones para pensar que las actitudes hacia la cohabitación no matrimonial en la sociedad española sean muy diferentes de las que quepa encontrar en los países centroeuropeos. 


\section{La familia española en el contexto de la Unión Europea}

TABla 3. Actitudes hacia las uniones de hecho. Porcentaje de respuestas a la pregunta: Hay gente que vive junta sin estar casada. ¿Esto le parece algo bueno, malo o algo que no debe juzgarse?

\begin{tabular}{|l|c|c|c|c|c|c|c|c|c|c|c|c|c|}
\hline & BE & DK & D & GR & E & F & IR & I & L & NL & P & UK & $\begin{array}{c}\text { UE } \\
\mathbf{1 2}\end{array}$ \\
\hline Es algo bueno & 26 & 15 & 25 & 23 & 20 & 24 & 19 & 10 & 38 & 20 & 22 & 13 & 19 \\
\hline Es algo malo & 12 & 6 & 12 & 36 & 13 & 8 & 26 & 19 & 11 & 10 & 21 & 14 & 14 \\
\hline No debe juzgarse & 59 & 80 & 55 & 40 & 66 & 66 & 51 & 68 & 48 & 68 & 53 & 71 & 63 \\
\hline No sabe / no contesta & 2 & 0 & 6 & 4 & 2 & 2 & 5 & 4 & 3 & 3 & 4 & 1 & 3 \\
\hline Total & 100 & 100 & 100 & 100 & 100 & 100 & 100 & 100 & 100 & 100 & 100 & 100 & 100 \\
\hline
\end{tabular}

Fuente: EUROBAROMETRO (1.993), Les Européens et la famille, Comission des Communautes Européennes, Bruselas, nro. 39 , p. 86

La valoración moral de las uniones de hecho cuando hay hijos resulta, por el contrario, más controvertida. La norma social de si hay hijos debe haber entonces matrimonio no es considerada en España vinculante por toda la población: mientras entre los jóvenes predominan quienes la rechazan (un $62 \%$ de los menores de 40 años), entre las generaciones más mayores, por el contrario, esta norma está plenamente vigente (un $83 \%$ de los mayores de 60 años muestran su adhesión a la misma) (CIS, 1994). La reprobación explícita de este tipo de marco para la materni$\mathrm{dad} /$ paternidad presenta una pauta muy similar en otras encuestas (CIS, 1992), aunque en la encuesta de de Miguel (1993: 219) sólo un tercio de los jóvenes entrevistados se mostraba explícitamente de acuerdo con la proposición "para tener hijos no hace falta estar casado». Comparativamente con otros países, su extensión es similar a la que cabe encontrar en países como Suiza o Austria, e inferior a la que muestran italianos, húngaros o checos (con porcentajes entre 55 y $73 \%$ de encuestados que desaprueban la paternidad/maternidad no matrimonial) (Palomba, 1995: 269)). Ahora bien, como se verá más adelante, cuando hay un proyecto familiar, esto es, cuando se quieren tener o se han tenido hijos las parejas cohabitantes tienden de hecho a casarse.

Esta privatización de los modos de entrada y formas de vida familiares no ha comportado, sin embargo, un rechazo del matrimonio. Todas las encuestas disponibles evidencian una consideración positiva o neutra del matrimonio por parte de la mayor parte de la población. La proporción de encuestados que declaran que eel matrimonio es una institución pasada de moda» se sitúa entre el 15 y el 20\%, según distintas encuestas (CIS, 1992; de Miguel, 1994; Alberdi, Flaquer e Iglesias, 1.994; CIS, 1995; CIS, 2002). Esta proporción es muy similar a la de otros países europeos como Italia, 
Austria, Suiza o Alemania (entre un 11 y un 22\%) e incluso de países en los que el proceso de desinstitucionalización de la familia se encuentra más avanzado, como Holanda (15\%) (Palomba, 1995: 266). Entre los jóvenes incluso se registra una tendencia oscilante entre quienes sostienen esta idea (el grado de acuerdo ha pasado del $37 \%$ en 1981 a algo menos del $21 \%$ en 1991 -de Miguel, 1993- pero nuevamente al 38\% según CIS (2002)), idea que, no obstante, va abandonándose a medida que se va dejando de ser joven. Cuestión diferente es, no obstante, qué lugar ocupa el rechazo o la validez del matrimonio en la biografía de pareja. Como puede observarse en la tabla 4, en el plano de las representaciones ideales, el modelo de matrimonio como fórmula de inicio de un proyecto de vida en común es minoritario entre los jóvenes, estando más extendida la fórmula de la cohabitación sin excluir, no obstante, el matrimonio posterior como fórmula confirmatoria del compromiso mutuo. A medida que va dejándose de ser joven, el matrimonio como forma de entrada en la vida en común va ganando peso, probablemente por estar más asociado a la formación de una familia y un patrimonio común. El matrimonio ha perdido así fuerza vinculante, pero no aceptación social, siendo las uniones de hecho percibidas mayoritariamente, tanto por mayores como por los jóvenes, como «matrimonios a prueba» más que como «alternativas al matrimonio».

TABLA 4. Formas ideales de materialización de un proyecto de vida en común: En su opinión, e independientemente de su situación actual, ¿cuál de las siguientes formas de convivencia le parece mejor para una pareja estable?

\begin{tabular}{|l|c|c|c|c|}
\hline & $\mathbf{1 8 - 2 9}$ & $\mathbf{3 0 - 4 9}$ & $\mathbf{5 0} \mathbf{y}+$ & Total \\
\hline Casarse "por la Iglesia" & 35 & 44 & 74 & 64 \\
\hline Casarse "por lo civil" & 7 & 12 & 9 & 9 \\
\hline $\begin{array}{l}\text { Vivir juntos y luego casarse "por la } \\
\text { Iglesia" }\end{array}$ & 19 & 8 & 3 & 9 \\
\hline Vivir juntos y luego casarse "por lo civil" & 12 & 12 & 3 & 8 \\
\hline Vivir juntos sin estar casados & 22 & 13 & 4 & 11 \\
\hline No vivir juntos & 1 & 1 & 1 & 1 \\
\hline Otras respuestas & 3 & 6 & 4 & 4 \\
\hline No sabe / no contesta & 2 & 4 & 4 & 4 \\
\hline Total & 100 & 100 & 100 & 100 \\
\hline
\end{tabular}

Nota: En el barómetro de mayo de 1997 también se formuló esta misma pregunta y la distribución de respuestas fue muy similiar.

Fuente: CIS, Barómetro de marzo, Estudio 2.283, Madrid, marzo de 1998.

Coherentemente con esta privatización de los modos de entrada a la vida familiar se ha producido una aceptación generalizada del divorcio 


\section{La familia española en el contexto de la Unión Europea}

como vía de salida a una situación familiar insatisfactoria para los cónyuges. Las actitutes ante el divorcio en España han evolucionado también rápidamente (Iglesias de Ussel, 1998) y en la actualidad las causas que pueden justificar un divorcio son en buena medida similares a las que lo justifican para los ciudadanos de otros países de la Unión Europea con una legislación sobre el divorcio más antigua. En España, como en el resto de los países, el divorcio se justifica ante todo por razones socialmente consideradas graves, concretamente por la violencia conyugal $(68 \%)$, si bien uno de cada tres encuestados sigue sin considerar posible el divorcio ni siquiera por esta causa (frente a menos del $20 \%$ en la mayoría de los países de la UE e incluso del $8 \%$ en Dinamarca). Pero lo más significativo no es el reconocimiento del divorcio para estos casos en los que antaño legalmente se permitía la separación. Lo novedoso, la otra cara de la privatización y que es la que ha hecho que se perciba la cohabitación prematrimonial como una opción deseable antes de contraer matrimonio, procede de la aceptación del divorcio «cuando no existe ya comunicación entre los cónyuges» (60\% de acuerdo), «cuando las personalidades individuales son incompatibles» (47\%) o cuando «no hay ya intereses comunes, salvo la seguridad económica» (41\%). Estas proporciones, aunque algo inferiores a la media comunitaria $(65,56$ y $47 \%$ respectivamente) y similares a las que se registran en países centroeuropeos como Alemania o el Reino Unido, ponen de manifiesto una profunda modificación de la concepción del matrimonio dentro de la cultura familiar española hasta equipararla a las actitudes generales que existen en los países europeos centrales. El gran freno para el divorcio es en España, como en todos los demás países, y en una proporción muy similar (66\% frente a una media comunitaria del 62\%), la presencia de hijos pequeños y en mucha menor medida la presencia de hijos adolescentes (38 frente a $34 \%$ ). Todas las demás posibles causas (sentimiento de responsabilidad, sentimiento de fracaso, miedo a la soledad, las dificultades económicas que comporta o la fuerza de las convicciones religiosas) no operan como frenos, al menos en el plano ideal y normativo (que no en la realidad concreta), más que en una proporción pequeña de la población española y europea (para menos de un tercio de los encuestados). El perfil de las normas que frenan la divorcialidad no es así muy diferente del que rige en el resto de los países, tanto de aquellos con una divorcialidad alta como baja, por más que exista una mayor proporción de personas que no justifiquen el divorcio en ningún caso.

Conviene llamar la atención, no obstante, sobre el hecho de que a pesar de que la concepción del matrimonio ha conocido un ahondamiento en 


\section{Gerardo Meil Landwerlin}

su fundamentación afectiva en el marco de este proceso de postmodernización de las relaciones familiares, al tiempo que se producía la revolución sexual a la que hemos aludido, la insatisfacción de las relaciones sexuales en el seno del matrimonio continua sin ser considerada una causa que justifique un divorcio, a no ser que sea representativa de una crisis más profunda. La percepción del divorcio como una salida a unas relaciones sexuales insatisfactorias, sujetas a la norma de la fidelidad, no forma parte del horizonte familiar más que de una pequeña minoritaria en todos países de la Unión Europea, católicos y protestantes, del norte y del sur. Aunque hay diferencias según la edad y el status parental, la diferencia más importante está en si han cohabitado antes de casarse, viven en una unión de hecho o se han separado, en cuyo caso la insatisfacción sexual es vista por uno de cada tres encuestados (entre un 25 y un $36 \%$ ) como causa de divorcio. Pero incluso esta proporción no deja de ser sorprendente dada la centralidad que ha adquirido la satisfacción de las relaciones sexuales en los proyectos de vida en común. En este sentido, y a pesar del elevado ritmo de crecimiento de los divorcios, el matrimonio en Europa sigue estando estrechamente asociado a la estabilidad y constituye para la mayor parte de la población una experiencia única, como lo demuestra la muy reducida proporción de segundas y sucesivas nupcias (3,7\% de las parejas como media en la Unión Europea).

Como conclusión se puede señalar que la realidad familiar española en su dimensión cultural se ha postmodernizado y presenta unas características muy similares a las que cabe encontrar en el resto de países de la Unión Europea, tan similares que no cabe hablar de modelos culturales familiares diferentes, sino de acentos diferenciales. Más en concreto, los factores culturales que han llevado a la pluralización de los modos de vida en los países del centro y norte de Europa están igual de extendidos en España como en dichos países. Ahora bien, si la cultura familiar se ha postmodernizado, no ha sucedido lo mismo con los comportamientos efectivos, si bien la realidad familiar en este sentido esta conociendo un lento, pero profundo cambio.

\section{Una pluralización limitada de los modos de vida}

Aunque quepa hablar de una convergencia en el plano normativo, determinados aspectos relevantes de la vida familiar son marcadamente diferentes, mientras que las diferencias con otros países de la UE en otras dimensiones de la realidad familiar son menores. Así, mientras el des- 


\section{La familia española en el contexto de la Unión Europea}

censo en el número de matrimonios y el retraso en su constitución ha sido paralelo al que han conocido los demás países de la UE, las pautas en el proceso de emancipación de los jóvenes del hogar de sus padres son muy diferentes en España (y en los demás países del sur) de las que existen en los países del centro y norte de Europa. Mientras en los países nórdicos las uniones de hecho han pasado a convertirse en una institución específica, esto es, en un modelo social de organización de la convivencia entre los miembros de una pareja y en los países del centro de Europa se ha convertido en una fase del ciclo familiar previa al matrimonio por la que pasan la gran mayoría de los jóvenes cuando inician sus proyectos de vida en común, en los países del sur y en particular en España, aunque las uniones de hecho son un fenómeno emergente, su extensión es muy limitada, siendo utilizada, como se verá más adelante, sobre todo como fase previa al matrimonio.

Por otro lado, aunque en todos los países se ha registrado una reducción de la fecundidad hasta niveles muy alejados del reemplazo generacional, dentro de un régimen de fecundidad bajo, las diferencias de unos países a otros son marcadas, tanto si se considera desde el punto de vista de los indicadores sintéticos (como son el índice sintético de fecundidad) como si se consideran los distintos tamaños de las familias. Mientras en España, la inmensa mayoría de las parejas tiene al menos un niño, pero muy pocas más de dos, en otros países como Alemania la proporción de parejas sin hijos es relativamente alta, pero también es relativamente alta la proporción de familias con más de dos hijos. Por otro lado, también cabe encontrar diferencias muy marcadas en la fecundidad no matrimonial, que está directamente relacionada con la extensión relativa y los usos sociales que se hacen de las uniones de hecho.

Aunque la ruptura matrimonial por separación o divorcio ha conocido un fuerte crecimiento desde su instauración a comienzos de los ochenta, siendo mayor el crecimiento de las rupturas por mutuo acuerdo que aquéllas por causa legal, España (como los demás países del sur e Irlanda) se caracteriza por una frecuencia de rupturas mucho menor que la que conocen los demás países del centro y norte de Europa.

Roussel (1992) hablaba a comienzos de la década de los 90 de un abrigo de Arlequín para dar cuenta gráficamente de las profundas diferencias regionales que cabía encontrar en la UE a partir de los indicadores considerados anteriormente. Una década más tarde no hay razones para considerar que las pautas hayan cambiado sustancialmente, aunque se pueda discutir sobre el significado atribuible a los criterios de clasificación «bajo», «medio» y «alto». Lo que hay que preguntarse es el por qué de 
estas diferencias, si, como se ha tratado de ilustrar anteriormente, hay una convergencia muy grande en las actitudes y opiniones sobre las formas alternativas al modelo burgués de familia. Esta es una cuestión muy compleja que la sociología de la familia no ha abordado de forma sistemática y que tampoco puede abordarse aquí. La cuestión que en este contexto quiere plantearse, no obstante, sí está relacionada con ello y es ¿por qué en España el alcance de las uniones de hecho es más limitado que el que se da en los países del centro y norte de Europa? y, relacionado con ello, ¿qué uso social se hace de las uniones de hecho en España?

\section{El alcance de las uniones de hecho en España y en la UE}

En los proyectos de regulación legal de las parejas de hecho hay una polémica implícita y que ha sido abordada también en las correspondientes discusiones parlamentarias, sobre qué formas de convivencias en un mismo hogar deben considerarse como parejas o uniones de hecho. Por uniones de hecho se entenderá en este contexto aquellos proyectos de convivencia en pareja de personas de distinto sexo que se identifican como tales a los encuestadores que les interrogan sobre el particular, esto es, a aquellas uniones que se presentan a los demás y que, por tanto, se entienden a sí mismas como parejas no estando unidas por la institución del matrimonio.

Se trata de un fenómeno en expansión, que se ha ido extendiendo a lo largo de la estructura social, de forma que si antes era propio de las jóvenes generaciones de las grandes urbes y con niveles de estudios elevados, en la actualidad están más homogéneamente repartidas a lo largo de la estructura social, tanto en lo que se refiere al nivel de estudios como al lugar de residencia, así como en menor medida en relación a las edades (Meil, 2003).

Comparativamente con los países de nuestro entorno, sin embargo, como se ha señalado anteriormente, las uniones de hecho no están muy extendidas, lo cual quiere decir que su expansión ha sido mucho más lenta que en los países del centro y norte de Europa. Si a principios de los años 80 sólo en los países nórdicos estaban relativamente extendidas, pero no así en los demás países de la UE, a mediados de los 90 ya se habían generalizado como forma de inicio de la convivencia en pareja en todos los países del centro y norte de Europa, habiéndose convertido en muchos lugares ya en una institución diferenciada del matrimonio. 


\section{La familia española en el contexto de la Unión Europea}

TABLA 5. Porcentaje de mujeres que convivían en unión de hecho momento de la entrevista según su edad respecto al total de mujeres de cada grupo de edad y, entre paréntesis, como porcentaje del total de uniones (matrimoniales y no matrimoniales)

\begin{tabular}{|c|c|c|c|c|c|c|c|}
\hline & Total & $\mathbf{2 0 - 2 4}$ & $\mathbf{2 5 - 2 9}$ & $\mathbf{3 0 - 3 4}$ & $\mathbf{3 5 - 3 9}$ & $\mathbf{4 0 - 4 4}$ & $\mathbf{4 5 - 4 9}$ \\
\hline 1985 & $0.8(1.1)$ & $0.5(2.1)$ & $0.9(1.2)$ & $0.8(0.8)$ & $0.7(0.8)$ & $0.5(0.6)$ & $0.6(0.8)$ \\
\hline 1995 & $3,4(5,2)$ & $4,5(19,4)$ & $5,6(8,9)$ & $3,5(4,2)$ & $3,8(4,3)$ & $1,5(1,8)$ & $1,1(1,3)$ \\
\hline 1999 & $4,1(6,9)$ & $2,7(34,0)$ & $6,5(15,3)$ & $5,7(7,2)$ & $4,5(5,1)$ & $2,0(3,4)$ & $2,6(3,0)$ \\
\hline 2001 & $5,0(9,0)$ & $4,3(38,4)$ & $6,9(18,8)$ & $6,9(10,2)$ & $5,0(6,8)$ & $3,8(5,0)$ & $2,9(3,7)$ \\
\hline
\end{tabular}

Fuente: INE, Encuesta de fecundidad 1985 y 1999, Madrid; CIS, Encuesta fecundidad y familia (FFS/ONU), Estudios 2121 y 2182, noviembre 1994 y 1995; INE, Censo de población 2001.

TABLA 6. Porcentaje de parejas que viven en una unión de hecho sobre el total que vive en una unión según tramos de edad

\begin{tabular}{|l|c|c|c|c|}
\hline \multirow{2}{*}{} & \multicolumn{2}{|c|}{$\begin{array}{c}\text { Población de 16 a 29 años } \\
\text { en pareja }\end{array}$} & \multicolumn{2}{c|}{$\begin{array}{c}\text { Población de 16 y más } \\
\text { años en pareja }\end{array}$} \\
\cline { 2 - 5 } & $\mathbf{1 9 9 4}$ & $\mathbf{1 9 9 8}$ & $\mathbf{1 9 9 4}$ & 1998 \\
\hline Grecia & $\mathbf{9}$ & 8 & 2 & 1 \\
\hline Italia & 6 & 11 & 2 & 2 \\
\hline España & 14 & 12 & 3 & 3 \\
\hline Irlanda & 11 & 29 & 3 & 4 \\
\hline Portugal & 10 & 15 & 3 & 5 \\
\hline Luxemburgo & 28 & 27 & 10 & 7 \\
\hline Austria & - & 30 & - & 9 \\
\hline Unión Europea-15 & 31 & 33 & 8 & 9 \\
\hline Alemania & 30 & 35 & 9 & 9 \\
\hline Bélgica & 27 & 35 & 10 & 9 \\
\hline Francia & 46 & 41 & 14 & 10 \\
\hline Reino Unido & 38 & 53 & 11 & 13 \\
\hline Países Bajos & 54 & 56 & 13 & 15 \\
\hline Dinamarca & 72 & 57 & 25 & 17 \\
\hline Finlandia & - & 61 & - & 21 \\
\hline Suecia & - & 70 & - & 23 \\
\hline
\end{tabular}

Leyenda: $\mathrm{El} 31 \%$ de las parejas en UE-15 cuyo informante tiene entre 16 y 29 años son una unión de hecho en 1994. El 69\% restante están unidos por el vínculo matrimonial.

Fuente: Eurostat (1998), Social Portrait of Europe, Luxemburgo y Eurostat (2004), The Social Situation in European Union, Luxemburgo, basado en datos del Panel de Hogares de la Unión Europea.

El estudio de las uniones de hecho desde un punto de vista transversal, esto es, a partir de la situación de pareja en un momento temporal determinado, proporciona una imagen distorsionada sobre el alcance y el uso social que se hace de este tipo de convivencias, pues las convivencias no matrimoniales pueden ser tanto una alternativa al matrimonio como una fase previa al mismo. Según sea la fuente que se utilice, la proporción de los que han convivido de hecho antes de casarse es entre el doble y el triple de los que conviven no matrimonialmente en el momento de la entrevista. 
Aunque teóricamente cabe imaginar múltiples combinaciones de las convivencias no matrimoniales y matrimoniales, aquéllas son utilizadas en España fundamentalmente bien como forma de inicio de la primera convivencia, bien como forma de materialización de un segundo o sucesivo proyecto de vida en común. Mientras que la primera unión se inicia mayoritariamente a través del matrimonio, si el primer proyecto de vida en común se rompe y se materializa un segundo proyecto, éste se inicia en la gran mayoría de los casos mediante una unión de hecho. Lo mismo sucede si éste también se frusta y se inicia un tercer proyecto. Dada la limitada propensión a iniciar un nuevo proyecto de vida en común tras una ruptura, la mayor parte de las parejas de hecho en un momento determinado del tiempo, al menos hasta el presente, son parejas que no se forman tras una unión anterior disuelta, sino que viven su primer (y eventualmente único) proyecto de vida en común $(65,2 \%$ en el caso de los varones y $61,8 \%$ en el caso de las mujeres, según la encuesta FFS/ONU de 1995 del CIS).

TABLA 7. Formas de inicio de inicio de las distintas convivencias de la población de 18 a 49 años alguna vez en pareja en 1995

\begin{tabular}{|l|r|r|r|}
\hline & $\mathbf{1}^{\mathbf{a}}$ relación & $\mathbf{2}^{\mathbf{a}}$ relación & $\mathbf{3}^{\mathbf{a}}$ relación \\
\hline Hombres & & & - \\
\hline Matrimonio & 80.0 & 23.1 & 21.2 \\
\hline Unión de hecho con matrimonio posterior & 8.6 & 12.1 & 69.7 \\
\hline Unión de hecho & 11.4 & 63.7 & 100 \\
\hline Total & 100 & 100 & 33 \\
\hline $\mathrm{N}$ & 1.180 & 91 & \\
\hline Mujeres & & & - \\
\hline Matrimonio & 88.4 & 12.7 & - \\
\hline Unión de hecho con matrimonic posterior & 5.2 & 23.0 & 75.0 \\
\hline Unión de hecho & 6.4 & 64.3 & 100 \\
\hline Total & 100 & 100 & 12 \\
\hline $\mathrm{N}$ & 2.833 & 126 & \\
\hline
\end{tabular}

Fuente: Elaboración propia sobre datos de CIS, estudios 2.121 y 2.182, Encuesta de Fecundidad y Familia (FFS/ONU), noviembre 1994 / 1995.

Estos datos esconden, no obstante, el profundo cambio que se está produciendo en este sentido, pues son las generaciones jóvenes las que cada vez menos inician su proyecto de vida en común mediante un ma- 


\section{La familia española en el contexto de la Unión Europea}

trimonio directo y tanto más cuanto antes inician este proyecto de vida. No obstante, comparativamente con el resto de países de la UE, España se caracteriza por un nivel relativamente bajo. En este sentido, la menor presencia de uniones de hecho en el panorama español no sólo guarda relación con una menor extensión del divorcio, sino que también hay marcadas diferencias por lo que se refiere al inicio de la primera convivencia, que sigue dándose mayoritariamente a través del matrimonio directo sin convivencia previa alguna.

TABLA 8. Forma de inicio de la primera convivencia según la edad en 1995.

\begin{tabular}{|l|r|r|r|r|r|r|r|r|}
\hline & $\mathbf{1 8 - 1 9}$ & $\mathbf{2 0 - 2 4}$ & $\mathbf{2 5 - 2 9}$ & $\mathbf{3 0 - 3 4}$ & $\mathbf{3 5 - 3 9}$ & $\mathbf{4 0 - 4 4}$ & $\mathbf{4 5 - 4 9}$ & TOTAL \\
\hline Hombres & & & & & & & & \\
\hline Matrimonio & - & 62,5 & 68,5 & 72,1 & 82,7 & 87,4 & 91,8 & 79,9 \\
\hline $\begin{array}{l}\text { Unión de hecho con } \\
\text { matrimonio posterior }\end{array}$ & - & 7.5 & 9.5 & 12.1 & 8.0 & 8.6 & 5.0 & 8.6 \\
\hline $\begin{array}{l}\text { Unión de hecho sin } \\
\text { matrimonio posterior }\end{array}$ & - & 30.0 & 22.5 & 15.8 & 9.3 & 3.6 & 4.2 & 11.4 \\
\hline Total & 100 & 100 & 100 & 100 & 100 & 100 & 100 & 100 \\
\hline $\mathrm{N}$ & 2 & 40 & 168 & 272 & 237 & 222 & 239 & 1.180 \\
\hline Mujeres & 38.9 & 69,2 & 80,4 & 86,9 & 92,3 & 93,9 & 97,0 & 88,3 \\
\hline Matrimonio & - & 4.7 & 8.2 & 7.7 & 4.4 & 3.5 & 2.1 & 5.2 \\
\hline $\begin{array}{l}\text { Unión de hecho con } \\
\text { matrimonio posterior }\end{array}$ & 55.6 & 26.2 & 11.4 & 5.5 & 3.3 & 2.6 & 0.9 & 6.4 \\
\hline $\begin{array}{l}\text { Unión de hecho sin } \\
\text { matrimonio posterior }\end{array}$ & 100 & 100 & 100 & 100 & 100 & 100 & 100 & 100 \\
\hline Total & 18 & 172 & 499 & 580 & 546 & 570 & 438 & 2.824 \\
\hline N
\end{tabular}

Fuente: Elaboración propia sobre datos de CIS, estudios 2.121 y 2.182 , Encuesta de Fecundidad y Familia (FFS/ONU), noviembre 1994 / 1995.

Para tratar de comprender por qué en España comparativamente tan pocos jóvenes comienzan su proyecto de vida en común mediante una unión de hecho, a pesar del profundo cambio que se ha registrado en las actitudes al respecto, hay que cuestionarse por los condicionantes que propician la opción por la unión de hecho frente al matrimonio.

Desde el punto de vista de la teoría del intercambio social se han interpretado las uniones de hecho como una estrategia fundamentalmente seguida por las mujeres para la búsqueda de un cónyuge y padre de sus hijos adecuado tanto en relación a su capacidad de obtener ingresos sufi- 


\section{Gerardo Meil Landwerlin}

cientes, como fundamentalmente para poner a prueba su capacidad para asumir responsabilidades familiares que faciliten en el futuro la conciliación de la vida familiar y la vida laboral. La conversión de la unión no matrimonial en una matrimonial se daría cuando las inversiones en el proyecto de vida en común son grandes y se busca garantizar estas inversiones a través de un aumento sustancial de los costes de ruptura. Las inversiones que en este sentido son más relevantes son, por un lado, la adquisición de una vivienda común y, sobre todo, la opción por la formación de una familia con la decisión de tener hijos. En otros términos, las uniones de hecho serían en este caso fundamentalmente «matrimonios a prueba» y se darían, no obstante, siempre que socialmente no estuviesen negativamente sancionados.

TABLA 9. Forma de inicio de la primera convivencia de las mujeres entrevistadas según su edad en el momento de la encuesta en distintos países alrededor de 1995

\begin{tabular}{|l|c|c|c|c|c|c|}
\hline & \multicolumn{3}{|c|}{ Mujeres de 25 a 29 años } & \multicolumn{3}{c|}{ Mujeres de 35 a 39 años } \\
\cline { 2 - 7 } & $\begin{array}{c}\text { Matrimonio } \\
\text { sin unión de } \\
\text { hecho } \\
\text { previa }\end{array}$ & $\begin{array}{c}\text { Unión de } \\
\text { hecho y } \\
\text { matrimonio }\end{array}$ & $\begin{array}{c}\text { Unión de } \\
\text { hecho sin } \\
\text { matrimonio }\end{array}$ & $\begin{array}{c}\text { Matrimonio } \\
\text { sin unión de } \\
\text { hecho } \\
\text { previa }\end{array}$ & $\begin{array}{c}\text { Unión de } \\
\text { hecho y } \\
\text { matrimonio }\end{array}$ & $\begin{array}{c}\text { Unión de } \\
\text { hecho sin } \\
\text { matrimonio }\end{array}$ \\
\hline Suecia (a) & 7 & 41 & 52 & 8 & 62 & 30 \\
\hline Noruega (a) & 24 & 40 & 35 & 62 & 30 & 7 \\
\hline Finlandia & 17 & 43 & 40 & 31 & 46 & 23 \\
\hline Francia & 12 & 30 & 58 & 48 & 34 & 19 \\
\hline Austria & 19 & 41 & 40 & 30 & 42 & 28 \\
\hline Suiza & 19 & 44 & 37 & 30 & 52 & 18 \\
\hline $\begin{array}{l}\text { Alemania } \\
\text { Occidental }\end{array}$ & 16 & 38 & 46 & 38 & 33 & 29 \\
\hline $\begin{array}{l}\text { Alemania } \\
\text { del Este }\end{array}$ & 15 & 35 & 50 & 21 & 26 & 53 \\
\hline Italia & 86 & 8 & 6 & 91 & 5 & 4 \\
\hline España & 80 & 8 & 12 & 91 & 4 & 5 \\
\hline Letonia & 50 & 34 & 17 & 67 & 26 & 8 \\
\hline Lituania & 75 & 9 & 16 & 78 & 10 & 12 \\
\hline Hungría & 76 & 14 & 10 & 84 & 9 & 7 \\
\hline Polonia & 95 & 3 & 2 & 96 & 3 & 1 \\
\hline
\end{tabular}

Nota: (a) Las cohortes de nacimiento de Suecia son las nacidas entre 1954 y 1964 y las de Noruega las nacidas entre 1950 y 1960.

Fuente: Kiernan, Kathleen (2001): «European Perspectives on Union Formation» en Waite, L. et al. (ed): The Ties that Bind, Aldine de Gruyter, Nueva York, p. 50, basado en los datos de la FFS/ONU. 


\section{La familia española en el contexto de la Unión Europea}

Para analizar la interrelación de los factores biográficos, culturales y materiales y aislar la influencia de cada uno de ellos es preciso realizar un análisis multivariable en el que se trata de determinar cuáles de estos factores condicionan realmente la opción a favor de la convivencia no matrimonial frente al matrimonio como fórmula de materialización del inicio del proyecto de vida en común. La única fuente de datos en la que puede realizarse un análisis de estas características es la encuesta FFS/ONU del CIS, realizada a mediados de los 90, que aunque no es muy actual, es la única que recoge información suficiente para realizar un análisis que incluya todas las dimensiones relevantes, pues la encuesta de fecundidad del INE de 1999 presenta importantes limitaciones en este sentido. Por otro lado, dado que se trata de una elección entre dos alternativas distintas hemos elegido la técnica de la regresión logística dicotómica en la que se trata de estimar la razón de probabilidades entre optar por la unión de hecho (independientemente de que ésta se legalice posteriormente con un matrimonio o no) frente a la de optar por el matrimonio directamente, sin convivencia previa. Valores superiores a 1 indican que la proporción de los que han iniciado su proyecto de vida en común mediante una convivencia no matrimonial en relación a los que lo han hecho mediante el matrimonio es superior a la proporción de la categoría de referencia. Aunque la razón de probabilidades no es exactamente igual a la probabilidad de vivir en unión de hecho, sí es proporcional, por lo que valores mayores que 1 significan una mayor probabilidad de iniciar el proyecto de vida en común mediante una unión de hecho que quienes se encuentran en la categoría de referencia (a la que se le asigna el valor 1). Por el contrario, valores por debajo de 1 significan una menor probabilidad de vivir en unión de hecho que los individuos que se encuentran en la categoría de referencia, no pudiendo haber valores por debajo de 0 .

Como variables que miden la dimensión ideológico-cultural en relación a la importancia concedida al matrimonio como institucionalización del compromiso mutuo se ha considerado, por una parte, la frecuencia de asistencia a oficios religiosos, bajo el supuesto de que quienes estén más vinculados a la práctica religiosa cotidiana más propensos serán a optar por el matrimonio frente a la cohabitación. Por otro lado, y dado que también se recogen actitudes hacia el matrimonio, la maternidad en solitario y el divorcio, también se han incluido estos indicadores bajo el supuesto de que cuanto menor importancia se conceda al vínculo matrimonial (el matrimonio es una institución anticuada), más se acepte la maternidad en solitario como una opción vital válida (si una mujer quiere tener un 
hijo por su cuenta, y no quiere tener una relación estable con un hombre, debería poder hacerlo) y menos objeciones se planteen en relación al divorcio (la falta de amor es razón suficiente para romper una relación de pareja), más a favor se está de la desinstitucionalización de los vínculos de pareja y, por tanto, más probable es que se haya optado por la unión de hecho como fórmula para iniciar el proyecto de vida en común. Como variables que miden las inversiones importantes en el proyecto de vida en común al que hemos aludido anteriormente se han considerado el régimen de propiedad de la vivienda y la tenencia de hijos. Por lo que se refiere al régimen de propiedad de la vivienda, aunque la pregunta se refería al régimen de tenencia en el momento de la entrevista y no cuando se inició el proyecto de vida en común, es sabido, y así lo hemos podido constatar en otro estudio (Meil, 2001), que la adquisición de la vivienda se produce mayoritariamente en paralelo a la decisión de materializar un proyecto de vida en común, siendo una proporción limitada quienes acceden a la propiedad con posterioridad. En el caso de los hijos, para obviar el problema de los calendarios diversos en las opciones por la tenencia de hijos, y dado que existe la información al respecto, se ha calculado no sólo si se tienen hijos comunes o no, sino cuando aparecen éstos una vez iniciada la biografía en común, de forma que si los hijos nacen en fechas próximas al inicio de la unión puede partirse del supuesto de que hay una voluntad de formar una familia, mientras que si no se tienen hijos o estos aparecen tarde en la biografía en común (se ha establecido el límite en los 3 años de convivencia) no hay una voluntad expresa e inmediata de formar una familia, pudiéndose suponer que o bien hay una actitud de rechazo explícito a la tenencia de hijos, o bien un período de prueba antes de comprometerse con una nueva vida. Esta última interpretación no tiene por qué darse en todos los casos, pues es perfectamente posible, y de hecho cada vez más frecuente, que haya una voluntad de tener hijos pero ésta no pueda materializarse o sólo tardíamente, bien por motivaciones económicas o físicas. No obstante, es de suponer que estos casos son la excepción más que la norma, por lo que no resulta excesivamente sobreinterpretado el significado que atribuimos a este indicador. Además de estas variables explicativas hemos considerado también como variables de control el lugar de residencia y la edad a la que se inicia la convivencia y como variables explicativas adicionales la experiencia de separación de los padres, la disponibilidad de recursos económicos para materializar un proyecto de vida en común (tenencia de un trabajo antes de iniciar la convivencia) y el nivel educativo. El nivel educativo puede considerarse una variable representativa tanto de actitudes culturales 


\section{La familia española en el contexto de la Unión Europea}

como de voluntad de desarrollo de un proyecto laboral y profesional propio, particularmente en el caso de las mujeres, de forma que cuando mayor es el nivel educativo de las mujeres más probable es que quiera conciliar vida familiar con vida laboral, tal como se ha demostrado extensamente en las pautas de incorporación de la mujer al mercado de trabajo. Y es en este último sentido en el que se interpretaran los datos.

TABLA 10. Forma de inicio de la primera convivencia: modelo de regresión logística binomial de los factores que influyen la probabilidad de que la primera unión comience mediante una unión de hecho. Entrevistada mujer

\begin{tabular}{|c|c|c|c|c|c|}
\hline Entrevistada & $\begin{array}{c}\text { España } \\
\text { Mujer } \\
\end{array}$ & $\begin{array}{c}\text { Alemania } \\
\text { Mujer }\end{array}$ & & $\begin{array}{c}\text { España } \\
\text { Mujer } \\
\end{array}$ & $\begin{array}{c}\text { Alemania } \\
\text { Mujer }\end{array}$ \\
\hline $\begin{array}{l}\text { Cohorte de } \\
\text { nacimiento } \\
1945-1949 \\
1950-1954 \\
1955-1959 \\
1960-1964 \\
1965-1969 \\
1970-1974 \\
1975-1977 \\
\end{array}$ & $\begin{array}{l}1 \\
1.5 \\
1.8 \\
2.2^{*} \\
2.9^{* *} \\
4.2^{* *} \\
9.9^{* *}\end{array}$ & $\begin{array}{l}1 \\
1.9^{* * * *} \\
3.7^{* * * *} \\
4.6^{* * * *} \\
6.9^{* * * *}\end{array}$ & $\begin{array}{l}\text { ¿La falta de amor es razón } \\
\text { para romper una relación } \\
\text { de pareja? } \\
\text { Razón suficiente } \\
\text { Razón insuficiente }\end{array}$ & $\begin{array}{l}0.9 \\
1\end{array}$ & $\begin{array}{l}1.1 \\
1\end{array}$ \\
\hline $\begin{array}{l}\text { Tamaño municipio de } \\
\text { residencia: }\end{array}$ & $1.4^{* * * *}$ & $1.08 * * *$ & $\begin{array}{l}\text { Asistencia a oficios } \\
\text { religiosos: } \\
\text { Semanal } \\
\text { Esporádica } \\
\text { Ocasional o nunca }\end{array}$ & $\begin{array}{l}0.3^{* * * *} \\
0.6^{* * *} \\
1\end{array}$ & $\begin{array}{l}0.2^{* * * *} \\
0.6^{* * * *} \\
1\end{array}$ \\
\hline $\begin{array}{l}\text { ¿Se han separado los } \\
\text { padres? } \\
\text { Sí } \\
\text { No } \\
\end{array}$ & $\begin{array}{l}3.7 * * * \\
1 \\
\end{array}$ & $\begin{array}{l}1.6 * * * * \\
1\end{array}$ & $\begin{array}{l}\text { Régimen de tenencia de la } \\
\text { vivienda: } \\
\text { En propiedad } \\
\text { Alquilada o cedida }\end{array}$ & $\begin{array}{l}1 \\
1.8 * * \\
\end{array}$ & $\begin{array}{l}1 \\
1.3^{*}\end{array}$ \\
\hline $\begin{array}{l}\text { Nivel de estudios: } \\
\text { Primario o menos } \\
\text { Secundario } \\
\text { Superior }\end{array}$ & $\begin{array}{l}1 \\
1.4^{*} \\
2.6^{* * * *}\end{array}$ & $\begin{array}{l}1 \\
0.7 * \\
1.05\end{array}$ & $\begin{array}{l}\text { Tenencia de hijos: } \\
\text { Sin hijos } \\
\text { Hijo/a mayor nacido antes } \\
\text { inicio de la unión } \\
\text { Ibidem nacido entre } 0 \text { y } 9 \\
\text { meses después } \\
\text { Ibidem nacido entre } 10 \text { y } 36 \\
\text { meses después } \\
\text { Ibidem nacido después de } \\
36 \text { meses }\end{array}$ & $\begin{array}{l}7.1^{* * * *} \\
1.7 \\
0.3^{* *} \\
1 \\
2.3^{* * *}\end{array}$ & $\begin{array}{l}2.6^{* * * *} \\
0.7^{* *} \\
0.5^{* * *} \\
1 \\
3.2^{* * * *}\end{array}$ \\
\hline $\begin{array}{l}\text { Actitud hacia mater- } \\
\text { nidad en solitario: } \\
\text { En desacuerdo } \\
\text { De acuerdo }\end{array}$ & $\begin{array}{l}1 \\
1\end{array}$ & $\begin{array}{l}0.9 \\
1\end{array}$ & $\begin{array}{l}\text { Edad de inicio de la } \\
\text { convivencia: } \\
\text { Menos de } 20 \text { años } \\
\text { De } 20 \text { a } 24 \text { años } \\
\text { De } 25 \text { a } 29 \text { años } \\
\text { De } 30 \text { o más años }\end{array}$ & $\begin{array}{l}2.3^{* * * *} \\
1 \\
0.8 \\
2.3^{*}\end{array}$ & $\begin{array}{l}1.7^{* * * * *} \\
1 \\
1.2 \\
1.9^{* * * * * *}\end{array}$ \\
\hline $\begin{array}{l}\text { El matrimonio } \\
\text { institución pasada de } \\
\text { moda: } \\
\text { En desacuerdo } \\
\text { De acuerdo }\end{array}$ & $\begin{array}{l}0.4^{* * * *} \\
1\end{array}$ & $\begin{array}{l}0.6^{* * * *} \\
1\end{array}$ & $\begin{array}{l}\text { Bondad del ajuste: } \\
\text { Sensitividad : \% predicción } \\
\mathrm{y}=1 \\
\text { Especificidad: \% total de } \\
\text { aciertos } \\
\text { Pseudo R2 : Cox-Snell } \\
\text { Pseudo R2 : Nagelkerke }\end{array}$ & $\begin{array}{l}32 \\
91 \\
0 . .9 \\
0 . .38\end{array}$ & $\begin{array}{l}75 \\
71 \\
0.22 \\
0.29\end{array}$ \\
\hline
\end{tabular}

+ Nivel de significación del 10\%* Nivel de significación del 5\%, ** Nivel de significación del 1\%, *** Nivel de significación del 1\%o Cuando no figura el nivel de significación es superior al 10\%, lo que significa que no puede rechazarse la hipótesis nula de ausencia de relación entre las variables a explicar y explicativa. 
Nota: El nivel educativo se refiere en el caso alemán a la cualificación profesional lograda (sin cualificación o básica a cualificación universitaria). La edad de inicio de la convivencia se refiere en la encuesta española al entrevistado/a y en la encuesta alemana a la pareja del entrevistado/a.

Fuente: Elaboración propia sobre datos de CIS, estudios 2.121 y 2.182 , Encuesta de Fecundidad y Familia (FFS/ONU), noviembre 1994 / 1995.

TABLA 11. Forma de inicio de la primera convivencia: modelo de regresión logística binomial de los factores que influyen la probabilidad de que la primera unión comience mediante una unión de hecho. Entrevistado varón

\begin{tabular}{|c|c|c|c|c|c|}
\hline Entrevistado & $\frac{\text { España }}{\text { Varón }}$ & $\begin{array}{c}\text { Alemania } \\
\text { Varón }\end{array}$ & & $\frac{\text { España }}{\text { Varón }}$ & $\begin{array}{c}\text { Alemania } \\
\text { Varón }\end{array}$ \\
\hline $\begin{array}{l}\text { Cohorte de nacimiento: } \\
1945-1949 \\
1950-1954 \\
1955-1959 \\
1960-1964 \\
1965-1969 \\
1970-1974 \\
1975-1977 \\
\end{array}$ & $\begin{array}{l}1 \\
0.9 \\
0.8 \\
1.2 \\
0.8 \\
0.6 \\
0.8\end{array}$ & $\begin{array}{l}1 \\
2.2^{* * * *} \\
3.1^{* * * *} \\
3.3^{* * * *} \\
2.9^{* * * *}\end{array}$ & $\begin{array}{l}\text { ¿La falta de amor es razón } \\
\text { para romper una relación } \\
\text { de pareja? } \\
\text { Razón suficiente } \\
\text { Razón insuficiente }\end{array}$ & $\begin{array}{l}0.7 \\
1\end{array}$ & $\begin{array}{l}0.9 \\
1\end{array}$ \\
\hline $\begin{array}{l}\text { Tamaño municipio de } \\
\text { residencia: }\end{array}$ & $1.2^{*}$ & $1.03^{* * * *}$ & $\begin{array}{l}\text { Asistencia a oficios } \\
\text { religiosos: } \\
\text { Semanal } \\
\text { Esporádica } \\
\text { Ocasional o nunca }\end{array}$ & $\begin{array}{l}0.8 \\
0.5^{*} \\
1\end{array}$ & $\begin{array}{l}0.4^{* * * *} \\
0.6^{* * * *} \\
1\end{array}$ \\
\hline $\begin{array}{l}\text { ¿Se han separado los } \\
\text { padres? } \\
\text { Sí } \\
\text { No }\end{array}$ & $\begin{array}{l}2.5^{*} \\
1\end{array}$ & $\begin{array}{l}1.3 \\
1\end{array}$ & $\begin{array}{l}\text { Régimen de tenencia de la } \\
\text { vivienda: } \\
\text { En propiedad } \\
\text { Alquilada o cedida }\end{array}$ & $\begin{array}{l}1 \\
1.5^{*}\end{array}$ & $\begin{array}{l}1 \\
1\end{array}$ \\
\hline $\begin{array}{l}\text { Nivel de estudios: } \\
\text { Primario o menos } \\
\text { Secundario } \\
\text { Superior }\end{array}$ & $\begin{array}{l}1 \\
2.1^{* * *} \\
3.6^{* * *}\end{array}$ & $\begin{array}{l}1 \\
0.4 \\
1.1\end{array}$ & $\begin{array}{l}\text { Tenencia de hijos: } \\
\text { Sin hijos } \\
\text { Hijo/a mayor nacido antes } \\
\text { inicio de la unión } \\
\text { Ibidem nacido entre } 0 \text { y } 9 \\
\text { meses después } \\
\text { Ibidem nacido entre } 10 \text { y } \\
36 \text { meses después } \\
\text { Ibidem nacido después de } \\
36 \text { meses }\end{array}$ & $\begin{array}{l}12.0^{* *} \\
1.7 \\
0.6 \\
1 \\
3.8^{* * * *} \\
\end{array}$ & $\begin{array}{l}1.7^{* * * *} \\
0.9 \\
0.4^{* *} \\
1 \\
2.5^{* * * *}\end{array}$ \\
\hline $\begin{array}{l}\text { Actitud hacia la } \\
\text { maternidad en solitario: } \\
\text { En desacuerdo } \\
\text { De acuerdo }\end{array}$ & $\begin{array}{l}1.1 \\
1\end{array}$ & $\begin{array}{l}1 \\
1\end{array}$ & $\begin{array}{l}\text { Edad de inicio de la } \\
\text { convivencia: } \\
\text { Menos de } 20 \text { años } \\
\text { De } 20 \text { a } 24 \text { años } \\
\text { De } 25 \text { a } 29 \text { años } \\
\text { De } 30 \text { o más años }\end{array}$ & $\begin{array}{l}5.2^{* * * *} \\
1 \\
0.5^{* * *} \\
0.6\end{array}$ & $\begin{array}{l}1.2+ \\
1 \\
1.3^{*} \\
2.6^{* * *}\end{array}$ \\
\hline $\begin{array}{l}\text { El matrimonio institu- } \\
\text { ción pasada de moda: } \\
\text { En desacuerdo } \\
\text { De acuerdo }\end{array}$ & $\begin{array}{l}0.5^{* * *} \\
1\end{array}$ & $\begin{array}{l}0.4^{* * * *} \\
1\end{array}$ & $\begin{array}{l}\text { Bondad del ajuste: } \\
\text { Sensitividad : \% predicción } \\
\text { y=1 } \\
\text { Especificidad: \% total de } \\
\text { aciertos } \\
\text { Pseudo R2 : Cox-Snell } \\
\text { Pseudo R2 : Nagelkerke }\end{array}$ & $\begin{array}{l}44 \\
85 \\
0.27 \\
0.43\end{array}$ & $\begin{array}{l}85 \\
69 \\
0.18 \\
0.24\end{array}$ \\
\hline
\end{tabular}

+ Nivel de significación del 10\%* Nivel de significación del 5\%, ** Nivel de significación del 1\%, *** Nivel de significación del 1\%o Cuando no figura el nivel de significación es superior al $10 \%$, lo que significa que no puede rechazarse la hipótesis nula de ausencia de relación entre las variables a explicar y explicativa.

Nota: El nivel educativo se refiere en el caso alemán a la cualificación profesional lograda (sin cualificación o básica a cualificación universitaria). La edad de inicio de la convivencia se refiere en la encuesta española al entrevistado/a y en la encuesta alemana a la pareja del entrevistado/a.

Fuente: Elaboración propia sobre datos de CIS, estudios 2.121 y 2.182, Encuesta de Fecundidad y

Familia (FFS/ONU), noviembre 1994 / 1995. 


\section{La familia española en el contexto de la Unión Europea}

Los resultados de este análisis se encuentran recogidos en la tabla 10 y 11 , donde se han recogido las estimaciones de la razón de probabilidades tanto para la encuesta realizada a mujeres como para la realizada a varones, que pueden tratarse como independientes al haber sido diseñadas y aplicadas de forma independiente. En dichas tablas puede observarse como la mayor parte de los supuestos de los que hemos partido anteriormente se cumplen, sobre todo, en el caso de las mujeres. La opción por iniciar el proyecto de vida en común mediante una convivencia no matrimonial se da más en las grandes urbes que en las ciudades intermedias, pequeñas o que en los pueblos, no habiendo diferencias estadísticamente significativas entre estas últimas, así como tanto más cuanto más jóvenes son las generaciones, salvo en el caso de los varones. La edad al inicio de la convivencia también es relevante y al respecto hay que llamar la atención sobre el hecho de que las uniones de hecho no son utilizadas como fórmulas de inicio de la primera unión principalmente por quienes retrasan mucho su proyecto de vida en común, sino ante todo por quienes lo adelantan apreciablemente respecto a la edad modal, por tanto, no por parte de parejas económicamente más o menos asentadas que pueden buscar garantizar una mayor autonomía, sino por parte de los muy jóvenes, que quieren emanciparse pronto de su familia y, como se verá, cuando no tienen un proyecto familiar inmediato.

Las variables culturales tienen una capacidad explicativa elevada pues tanto la frecuencia de asistencia a oficios religiosos como las actitudes hacia el matrimonio tienen un alto potencial explicativo. Así, la razón de probabilidades de inicio del proyecto de vida en común mediante una convivencia no matrimonial y, por tanto, la probabilidad de convivir de hecho es mucho más baja cuanto mayor sea el compromiso religioso, sobre todo, entre las mujeres, quienes parecen tener un poder de condicionamiento de las decisiones comunes mucho mayor, lo que no debe sorprender dado el mayor coste al que tienen que hacer frente en caso de ruptura del proyecto en común. La no valoración del matrimonio y su rechazo como una institución pasada de moda aumenta, como era de esperar, las probabilidades de que el proyecto en común no se sustancie bajo la forma matrimonial. Llamativo, por el contrario, resulta la ausencia de influencia de las actitudes hacia la maternidad en solitario y hacia el divorcio, lo que indica, claramente, que quienes inician su proyecto de vida en común a través del vínculo matrimonial no necesariamente son portadores de una concepción tradicional del matrimonio y la familia, sino que respetan en igual medida las opciones individuales que realizan las demás personas en esta dimensión de la vida individual que quienes eli- 
gen como forma de vida en común una unión de hecho. Visto desde otra perspectiva, estos datos indican también que la opción por el matrimonio como forma de inicio de la vida en común no implica necesariamente una concepción mucho más tradicional de la pareja y la familia en sentido amplio que quienes lo hacen a través de una unión de hecho, y viceversa. La opción por el matrimonio o la unión de hecho no parece ser indicativa de actitudes más o menos tradicionales frente al matrimonio y a la familia, al menos, en el plano de las opiniones y de los juicios de valor. ¿Por qué, entonces, siguen casándose las nuevas generaciones? Una de las razones que más claramente emergen del análisis realizado es la búsqueda de mayores garantías institucionales a la hora de asegurar importantes inversiones materiales y sociales en el proyecto de vida en común.

En efecto, la realización de importantes inversiones en el proyecto de vida en común también propicia que éste comience bajo la forma matrimonial, de suerte que quienes han adquirido la vivienda en propiedad tienen menor probabilidad de haber cohabitado antes, mientras que quienes inician su proyecto de vida en común mediante una unión de hecho lo hacen con significativamente mayor frecuencia en una vivienda en alquiler o eventualmente cedida a título gratuito. Dada la extendida cultura de propiedad de la vivienda en la que se reside y la generalizada consideración del pago de alquileres como una dilapidación de dinero, las diferencias en las razones de probabilidad son moderadas (no pasan de 2, lo que indica que una parte importante de parejas de hecho son propietarias de la vivienda en la que residen), sobre todo si se compara con el efecto de tener un hijo común. La probabilidad de convivir de hecho cuando no hay un proyecto familiar inmediato, controlados todos los demás factores, es mayor que cuando se quiere tener niños al poco de iniciada la convivencia. Así, la razón de probabilidades de iniciar el proyecto de vida en común mediante una unión de hecho cuando la pareja no tiene niños es 7 veces (encuesta a mujeres) o 12 veces superior (encuesta a varones) que cuando se ha tenido un hijo entre 9 y 36 meses después de iniciada la convivencia. De igual forma, la razón de probabilidades de inicio mediante convivencia no matrimonial es 2,3 veces (encuesta a mujeres) y 3,8 veces (encuesta a varones) mayor cuando los hijos aparecen después de tres años de iniciada la convivencia que cuando se sustancia al poco de iniciada ésta. La voluntad de tener hijos, por tanto, es un factor de extremada importancia para comprender la preferencia por el matrimonio frente a la unión de hecho, aunque no se estigmatice a quienes deciden tenerlos sin oficializar la unión, ni legalmente, ni en general tampoco socialmente. 


\section{La familia española en el contexto de la Unión Europea}

La experiencia familiar de ruptura actúa como factor disuasorio del matrimonio como fórmula de inicio del proyecto de vida en común, prefiriendo los hijos e hijas de padres separados en mayor medida la cohabitación previa, tal como sucede también en otros países de nuestro entorno (Kiernan, 2000). No obstante, entre los hijos de padres separados siguen siendo mayoría quienes sí institucionalizan su proyecto de vida en común antes de iniciarlo (64\% de las hijas y $58 \%$ de los hijos de padres divorciados), aunque al respecto hay que subrayar que no se puede partir del supuesto implícito de que en todos los casos el divorcio se ha dado antes del matrimonio de los hijos, sobre todo, entre las generaciones más mayores de encuestados, pues una de las características del divorcio en España es precisamente la elevada duración previa de los matrimonios antes de su disolución (Eurostat, 1997; 2003).

La tenencia de un proyecto profesional propio por parte de las mujeres determina también una mayor probabilidad de comenzar la primera unión a través de una cohabitación a fin de comprobar, probablemente, la capacidad de adaptación mutua a las nuevas obligaciones derivadas de la convivencia y las posibilidades de conciliación de la vida privada y la vida profesional. Así, la razón de probabilidades de inicio del proyecto de vida en común mediante una unión de hecho es casi 3 veces superior para las mujeres con estudios universitarios que para las mujeres con estudios primarios o menos y la razón de probabilidades de las mujeres con estudios secundarios es también 1,4 veces superior que la de las mujeres con estudios primarios, controlados los efectos de las demás variables. Los varones, en principio sorprendentemente, presentan la misma pauta, a pesar de que éstos no tienen cuestionado su proyecto profesional o laboral en función de las condiciones familiares en las que vivan (paternidad y pautas de división del trabajo doméstico). Aunque la variable educación ha sido considerada también como una variable representativa de valores y actitudes, también es cierto que en virtud de la homogamia mayoritaria entre la población (Meil, 1999: 169), también recoge indirectamente en muchos casos el nivel educativo de las mujeres de los entrevistados varones y, por tanto, las expectativas de un proyecto profesional propio por parte de éstas. Por tanto, cuando la mujer tiene un proyecto profesional propio es más probable que se inicie el proyecto de vida en común a través de una unión de hecho que si no lo tiene, lo que no significa, nuevamente, que la mayoría de las mujeres con estudios universitarios comiencen su biografía de pareja mediante una unión de hecho, pues sólo un 27,6\% de las encuestadas por el CIS así lo hicieron. 
En resumen, la probabilidad de iniciar un proyecto de vida en común mediante una unión de hecho está asociado a la ausencia de un proyecto familiar inmediato y a la no tenencia de la vivienda común en propiedad así como a la tenencia de un proyecto profesional propio por parte de las mujeres. Pero más allá de las inversiones que se hacen en el proyecto común, los valores y el entorno social en el que se vive condicionan la elección y hacen más o menos probable la opción por la cohabitación. Así, la práctica religiosa, más que las creencias religiosas, y las actitudes y valores sociales en relación al matrimonio y a la familia juegan un papel relevante, aunque no tanto las actitudes ante el divorcio u otras formas no tradicionales de familia, como la idea misma del matrimonio como forma de simbolizar y regular las relaciones entre los miembros de la pareja. Por otra parte, la opción por las uniones de hecho como forma de iniciar la vida en común es más probable que se dé en las grandes ciudades, si bien no es un fenómeno específico de éstas, pues, como se ha tenido ocasión de comprobar en el anterior capítulo, se han difundido a lo largo de toda la sociedad en la última década.

A efectos comparativos y con el fin de identificar qué factores explican el menor alcance de las uniones de hecho en España, cuando desde el punto de vista de las actitudes hacia el cambio familiar estarían dadas las condiciones culturales para una expansión igual de rápida de esta forma de convivencia que la que se ha dado en los países centroeuropeos, hemos realizado el mismo tipo de análisis con la base de datos correspondiente a Alemania, encontrándose los resultados obtenidos en las mismas tablas 10 y 11. En Alemania, como puede observarse en la tabla 9, las uniones de hecho se han generalizado rápidamente como forma de inicio de la primera y, tanto más, de las sucesivas uniones, de forma que en la actualidad es la forma más habitual de inicio de la primera convivencia entre las generaciones más jóvenes. ¿Qué diferencias presenta el análisis multivariable realizado y qué puede deducirse sobre la mayor propensión a casarse de las nuevas generaciones de españoles/as?

Más allá de la mayor rapidez en el cambio y de la igual tendencia a materializar el primer proyecto de vida en común mediante una unión de hecho en los núcleos urbanos más que en los rurales, se quiere centrar la discusión en dos dimensiones especialmente relevantes, a saber, por un lado, en los efectos de las variables culturales y, por otro, en la búsqueda de seguridad a través del matrimonio para las inversiones materiales, sociales y afectivas en el proyecto de vida común. Por lo que se refiere a la dimensión de la influencia de variables culturales, puede observarse que los factores culturales considerados, que son en principio los más rele- 
La familia española en el contexto de la Unión Europea

vantes para medir el alcance del cambio familiar en su dimensión cultural (práctica religiosa y actitudes hacia el cambio familiar -maternidad en solitario, matrimonio y divorcio por falta de amor-), presentan un potencial explicativo muy similar, tanto en lo que se refiere a la intensidad de los efectos, como a su dirección y a su nivel de significación. Tanto en el caso español como en el alemán, en la encuesta a mujeres así como en la de varones, las únicas variables relevantes para explicar la menor probabilidad de iniciar la primera convivencia mediante una unión de hecho $\mathrm{y}$, por tanto, la mayor probabilidad de casarse son la práctica religiosa y las actitudes hacia el matrimonio, de suerte que a mayor práctica religiosa y cuanto más positivas sean las actitudes hacia el matrimonio, tanto menos probable es que la primera unión se inicie mediante una unión de hecho. Dado que las diferencias en la frecuencia de asistencia a oficios religiosos así como el rechazo hacia el matrimonio no son sustancialmente diferentes ${ }^{3}$, la menor propensión a iniciar el primer proyecto de vida en común mediante una unión de hecho en España no puede explicarse apelando a variables culturales de estas características. Expresado en otros términos, la menor extensión de las uniones de hecho en España no puede explicarse por la mayor influencia de la Iglesia o del catolicismo o por unas actitudes más tradicionales en materia de matrimonio y familia, sino que está relacionado con la búsqueda de seguridad para las inversiones que se hacen en el proyecto común y con el retraso en la emancipación de los jóvenes del hogar paterno.

Ahora bien, como también puede observarse en la citada tabla, en Alemania el matrimonio está igualmente asociado con la búsqueda de garantías institucionales para las inversiones que se hacen en el proyecto común, pues la probabilidad de iniciar la primera unión mediante matrimonio en lugar de unión de hecho es muy superior cuando hay un proyecto familiar inmediato así como cuando se tiene la vivienda en propiedad (al menos en la encuesta a mujeres). De hecho, en la literatura alemana hay un consenso generalizado sobre el hecho de que las uniones de hecho son un preludio al matrimonio que se da cuando se materializa o se quiere materializar un proyecto familiar (Lauterbach, 1999). ¿Por qué entonces hay una menor extensión en España de la formación de las primeras uniones a través de la cohabitación? La razón creemos hay que buscarla, por un lado, en el hecho de que la emancipación del hogar paterno en España es muy tardía y, por otro lado, en la mayor búsqueda de garantías institucionales en la sociedad española. La emancipación tardía de los jóvenes lleva a que en el momento en el que quieren materializar su proyecto de vida en común, ello se asocie estrechamente con 
la voluntad de formación de una familia, por lo que la tenencia de hijos acontece en la mayor parte de los casos al poco tiempo de iniciada la convivencia, cuando no la antecede. Así, la mediana de tiempo entre el momento del matrimonio y el nacimiento del primer hijo se sitúa en 15,2 meses, no habiendo una tendencia clara hacia su retraso de una generación a otra. Dado el generalizado uso de métodos anticonceptivos y de relaciones sexuales prematrimoniales, la celebración del matrimonio está estrechamente vinculada a la voluntad de materialización de un proyecto familiar y estaría asociado a la búsqueda de una mayor garantía para la unión. Esta asociación se vería además reforzada por la generalizada aspiración a la propiedad de la vivienda común y la consideración casi universal del pago de un alquiler como «tirar el dinero», lo que lleva a que el acceso a la propiedad de la vivienda se dé no en fases más o menos avanzadas del ciclo de vida en común, sino como prerrequisito del inicio de la vida en común o al poco de iniciada ésta. Según el análisis que realizamos de la encuesta del INE Panel de hogares de 1993 (Meil, 2000: 132), sólo un $31 \%$ de los matrimonios que llevan conviviendo 2 o menos años vivían en régimen de alquiler, proporción que disminuye con la duración del mismo. Las inversiones que se hacen al inicio del proyecto de vida en común son, por tanto, muy grandes y el matrimonio se utilizaría entonces como fórmula para dotar de mayor fuerza vinculante al proyecto de vida en común, tanto simbólica como legalmente.

\section{Referencias bibliográficas}

Alberdi, I.; Flaquer, Ll. e Iglesias De Ussel, J (1.994): Parejas y Matrimonios. Actitudes, comportamientos y experiencias, Madrid, Ministerio de Asuntos Sociales

BECK, U. (1986): Risikogesellschaft, Suhrkamp, Frankfurt am Main (edición española, La sociedad del riesgo, Barcelona, Paidós, 1997)

BECK, U. y SoPP, P. (1997): «Individualisierung und Integration - Versuch einer Problemskizze» en BECK, U. y SoPP, P. (eds) (1997): Individualisierung und Integration. Neue Konfliktlinien und neuer Integrationsmodus?, Opladen, Leske + Budrich

BECK-GERNSHEIM, E. (1997): «Stabilität der Familie oder Stabilität des Wandels? Zur Dynamik der Familienentwicklung» en BECK, U. y SoPP, P. (eds) (1997): I Individualisierung und Integration. Neue Konfliktlinien und neuer Integrationsmodus?, Opladen, Leske + Budrich

- (1998): Was kommt nach der Familie?, Munich, Beck Verlag.

CAMPO, S. del y NAVARRO, M. (1985), Análisis sociológico de la familia española, Barcelona, Ariel.

CIS (Centro de Investigaciones Sociológicas) (1992): Población y Familia, estudio nro. 1990, marzo.

- (1994c): Familia, estudio nro. 2.113, septiembre 1.994, correspondiente al International Social Survey Programme, julio. 


\section{La familia española en el contexto de la Unión Europea}

- (1995): estudios 2.121 y 2.182, Encuesta de Fecundidad y Familia (FFS /ONU), noviembre 1994 / 1995.

- (2000): Juventud, Estudio 2.370, noviembre.

De Miguel, A. (1994): La sociedad española, 1993-94, Madrid, Alianza.

EuRobarometro (1993), Les Européens et la famille, Bruselas, Comission des Communautes Européennes, nro. 39.

IGLESIAS DE USSEL, J. (1998), La familia y el cambio político en España, Madrid, Tecnos.

KIERNAN, K. (2000): «European Perspective on Union Formation» en WAITE, L. J.; BACHRACH, Ch.; Hindin, M.; Thomson, E.; Thornton, A. (eds)(2000): The Ties that Bind, Perspectives on Marriage and Cohabitation, Nueva York, Aldine d Gruyter, pp. 4058.

MEIL, G. (2003) : Las uniones de hecho en España, Madrid, Centro de Investigaciones Sociológicas.

MeIL, G. (1999): La postmodernización de la familia española, Madrid, Acento editorial.

NAVE-HERZ, R.M. (1999): «Die Nichtehelichen Lebensgemeinschaftenals Beispiel gesellschaftlichen Differenzierung» en KLEIN, TH. Y LAUTERBACH, W. (eds.) (1999): Nichehelichen Lebensgemeinschaften. Analysen zum Wandel partnerschaft-licher Lebensformen, Opladen, Leske + Budrich, pp. 37-62.

ORIZO, FCO. ANDRÉS (1990), Los valores de los españoles, Madrid, Fundación Santa María.

Palomba, R. y Moors, H. (1995): Population, Family and Welfare: A Comparative survey of European Attitudes, Oxford, Claredon.

PARIS, I. (2000): «Relaciones afectivas» en DE MigUEL, A. (2000), Dos generaciones de jóvenes, 1960-1988, Madrid, INJUVE, pp. 189 y ss.

Roussel, L. (1989) : La famille incertaine, Paris, J. Odile.

\section{Notas}

1 Así, mientras que la proporción de varones que consideraban que sólo algunas veces está mal o incluso nunca estaba mal se elevaba al $24 \%$, entre las mujeres alcanzaba el $18 \%$, a lo que habría que añadir un 5 y $4 \%$ respectivamente de entrevistados que señalaron que no sabían o no contestaban (CIS, 1998).

${ }^{2}$ Las proporciones para el mismo tipo de preguntas pero referidas a un hijo varón del entrevistado arrojan proporciones similares, sin diferencias estadísticamente significativas respecto a las respuestas obtenidas para las hijas.

${ }^{3}$ Así, considerando el grupo de edad 20 a 39 años, que es el que cubre la encuesta FFS/ONU alemana, la asistencia semanal a oficios religiosos se da entre un $8,5 \%$ de los encuestados, mientras en la española se da en un $12 \%$ de los casos y la asistencia esporádica en un 63 y $59 \%$, correspondiendo el resto a una asistencia ocasional. Por lo que se refiere a la consideración del matrimonio como una institución pasada de moda, sólo un $24 \%$ de los/as encuestados/as alemanes así lo creía y entre los/as españoles/as el porcentaje era del $25 \%$. 